\title{
Optimization of a Three-Phase Tetrahedral High Voltage Transformer used in the Power Supply of Microwave
}

\author{
Mouhcine Lahame ${ }^{1}$, Mohammed Chraygane ${ }^{2}$, Hamid Outzguinrimt ${ }^{3,}$ Rajaa Oumghar $^{4}$ \\ Materials, Systems and Information of Technology Team (MSTI) \\ ESTA, Ibn Zohr University \\ Agadir, Morocco
}

\begin{abstract}
This article deals with the optimization of a threephase tetrahedral-type high voltage transformer, sized to supply three voltage-doubling cells and three magnetrons per phase. The optimization method used is based on an algorithm implemented in Matlab/Simulink to study the influence of transformer geometrical parameters on the electrical operation of the power supply. This study will allow to find reduced volume of transformer respecting the current constraints imposed by the magnetrons manufacturer. The choice of optimal solution is done by calculation of magnetrons powers in order to respect the nominal operation.
\end{abstract}

Keywords-Optimization; tetrahedral; voltage-doubling; transformer; magnetrons

\section{INTRODUCTION}

In the development study of power supplies for microwave applications, we always seek to find more powerful and optimal solutions in terms of installation space, cost of manufacture and maintenance. In this context, this work defines a method to optimize the three-phase HV transformer used in this kind of power supplies with nine magnetrons (three for each phase).

Unlike the old power supplies already developed, whether single-phase magnetron $800 \mathrm{Watts}-2450 \mathrm{Mhz}$ or three-phase of three magnetrons 2400Whats-2450Mhz [1-3]. This new technology of nine magnetrons is optimized compared to that previously developed [4]. It offers an identical microwave power of $7200 \mathrm{Watts}-2450 \mathrm{MHz}$. So it can use less optimized power supply to size a more powerful industrial microwave.

The design of this power supply is based on a three-phase HV transformer with magnetic shunts of tetrahedral type having a shell type structure. Each phase feeds three doublers cells giving a voltage which is suitable for the operation of the three magnetrons that delivers the microwaves [5]. The magnetic shunts of the transformer ensure the stability of the current in each magnetron in order to not exceed the values recommended by the manufacturer $\operatorname{Imax}<1.2 \mathrm{~A}$ and $\operatorname{Iavg} \leq$ $300 \mathrm{~mA}$.

This paper is divided in two sections. In the first, we present the model and the results obtained by simulation under Matlab/Simulink. In the second section, we study the influence of each geometrical parameter of the transformer on the operation of the power supply. This study will allow us to define the optimized algorithm based on the simultaneous variation of these parameters. This leads to various solutions that respect the criteria recommended by the magnetron manufacturer. The choice of the best solution is validated by the calculation of the volume as well as the comparison of the results obtained with those of the non-optimized power supply, taking into account the operation of magnetrons in full power.

\section{Modeling And Simulation of the Three-Phase High Voltage POWER SUPPLY WITH THREE-MAGNETRONS PER PHASE}

\section{A. Description and Modeling of Power Supply}

The general model of the three-phase HV power supply constitutes of a magnetic shunt transformer, doublers cells, and three magnetrons for each phase. The three-phase HV transformer is represented by three identical models of singlephase transformers coupled in star as shown in Fig. 1. Unlike conventional transformers, this special transformer contains intermediate magnetic shunts between the side columns and the central column, which allows to ensure the stabilization of the current in the magnetrons by the saturation of its magnetic circuit.

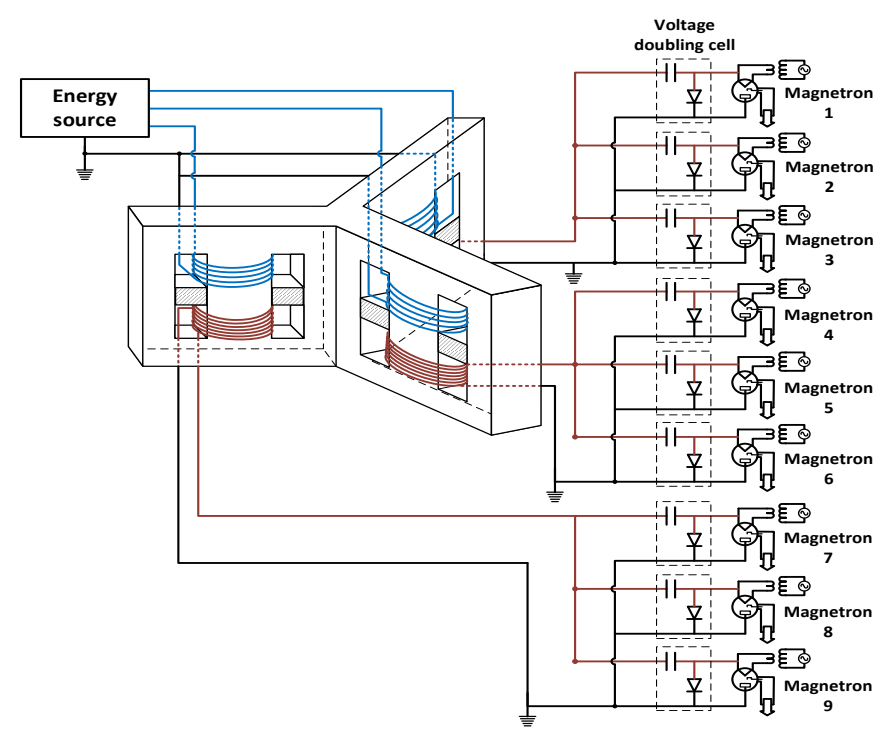

Fig 1. Three-Phase Power Supply of Three Magnetons per Phase having a Tetrahedral-Type Transformer. 
From the different electrical and magnetic equations already developed of this transformer [4], each phase is modeled as a quadruple in $\pi$, composed of three non-linear inductances on the primary, secondary and shunts sides. These inductances have a section $\mathrm{S}$, a length $\ell$ and a characteristic $\phi(\mathrm{i})$ which can be determined from the relation $L(i)=\frac{\mathrm{n}_{2} \phi(\mathrm{i})}{\mathrm{I}}$ and also the curve $\mathrm{B}(\mathrm{H})$ of the material transformer [6][7]. The different equations that determine the current and flux (I, $\phi)$ for each inductor are expressed as follows:

For primary inductance $L_{p}^{\prime}$ :

$\left\{\begin{array}{r}\phi_{p}=n_{2} \cdot S_{1} \cdot B \\ i_{p}^{\prime}=\frac{H \cdot \ell_{p}}{n_{2}}\end{array}\right.$

For secondary inductance $L_{s}$ :

$\left\{\begin{array}{c}\phi_{s}=n_{2} \cdot S_{2} \cdot B \\ i_{s}=\frac{H \cdot \ell_{s}}{n_{2}}\end{array}\right.$

For shunt inductance $L_{s h}^{\prime}$ :

$\left\{\begin{array}{c}\phi_{s h}=n_{2} \cdot S_{s h} \cdot B \\ i_{s h}^{\prime}=\frac{H \cdot \ell_{s h}}{n_{2}}\end{array}\right.$

Fig. 2 shows the different geometrical parameters of a single tetrahedral transformer phase.

- The width of the core: $\mathrm{a}=75 \mathrm{~mm}$

- The width of the magnetic circuit $: b=25 \mathrm{~mm}$

- Number of stacked sheets of the shunt : $\mathrm{n}_{3}=18$

- Number of primary windings : $\mathrm{n}_{1}=224$

- Number of secondary windings: $\mathrm{n}_{2}=2400$

- Height of shunts: $\mathrm{h}=0.5 \times \mathrm{n}_{3} \mathrm{~mm}$

- Primary and secondary core surface: $\mathrm{S}_{1}=\mathrm{S}_{2}=\mathrm{a} \times \mathrm{b}$

- Surface of shunt: $\mathrm{S}_{\mathrm{sh}}=\mathrm{b} \times \mathrm{h}$

- Thickness of the air gap: $\mathrm{e}=0.75 \mathrm{~mm}$

- $\ell_{p}=4.5 \times a$ (correspond to the path $\mathrm{ABCD}$ )

- $\ell_{s}=4.5 \times a$ (correspond to the path DAFE)

- $\ell_{s h}=(2.5 \times \mathrm{a}-2 \times \mathrm{e})$ (correspond to the path $\left.\mathrm{AD}\right)$

Each magnetron is presented by a model describing its operation which contains a diode with dynamic resistance $\mathrm{R}=$ $\Delta \mathrm{U} / \mathrm{I}=350 \mathrm{Ohm}$ and a threshold voltage $\mathrm{E}=3800 \mathrm{~V}$. Fig. 3 shows the general model of the power supply.

\section{B. Simulation of the Model}

The equivalent model of the three-phase HV power supply is implemented under Matlab/Simulink. The primary of the transformer is powered by a nominal voltage of $220 / 380 \mathrm{~V}$ with a phase shift of $2 \pi / 3$. Each non-linear inductance is modeled by Simulink blocks showing their operation. One of these blocks is used to interpolate the $\mathrm{B}(\mathrm{H})$ curve with the ANFIS neurofuzzy method [8-10]. Fig. 4 and 5 give the different currents/voltages curves of magnetrons, diodes, capacitors and transformer secondary obtained in a previously study [4]. These curves will be the comparison tool between the optimized and non-optimized power supplies.

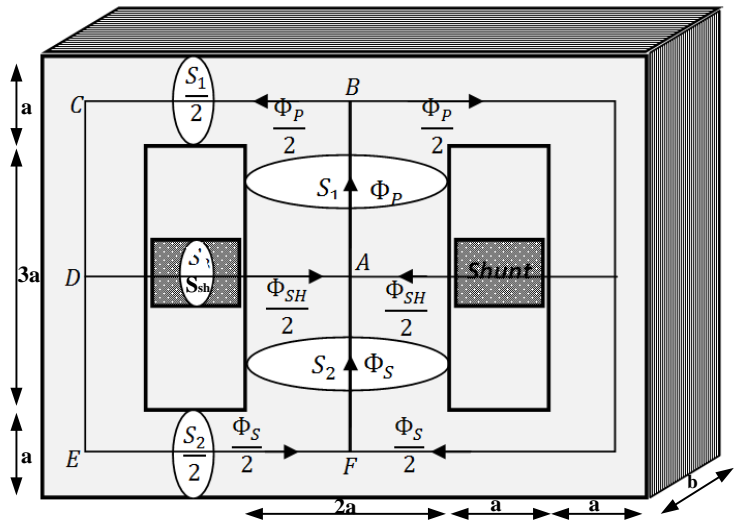

Fig 2. Geometry of a Single Tetrahedral Transformer Phase.

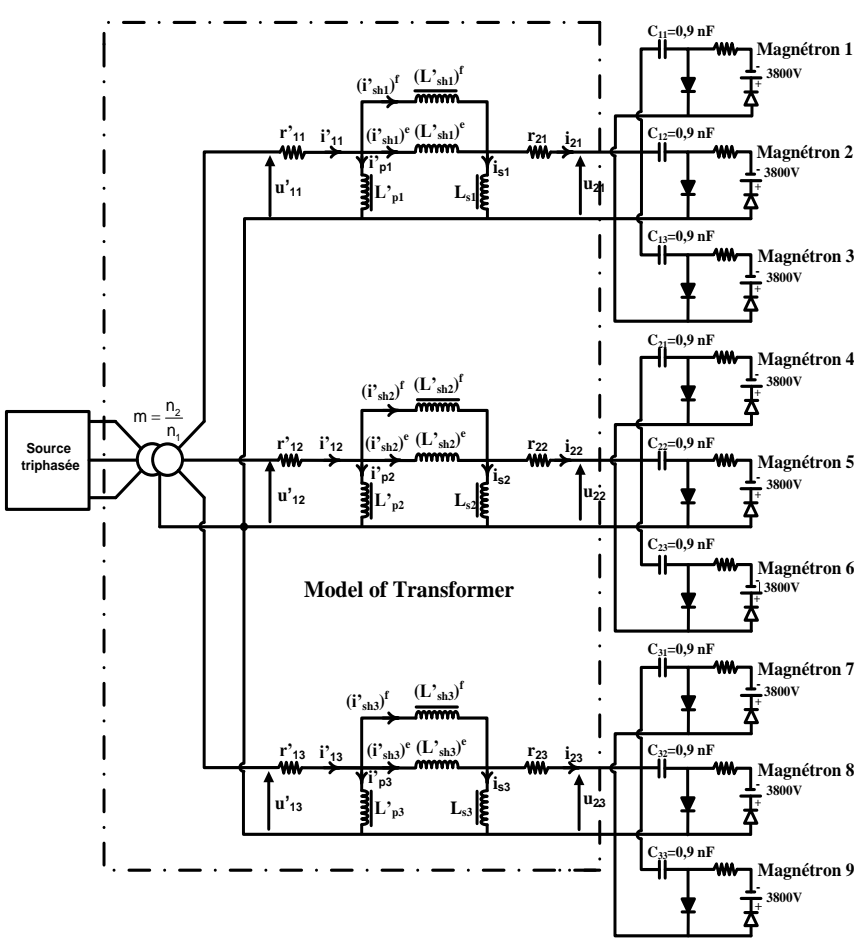

Fig 3. Electrical Diagram Equivalent of Three-phase High Voltage Power Supply for Three Magnetrons per Phase.

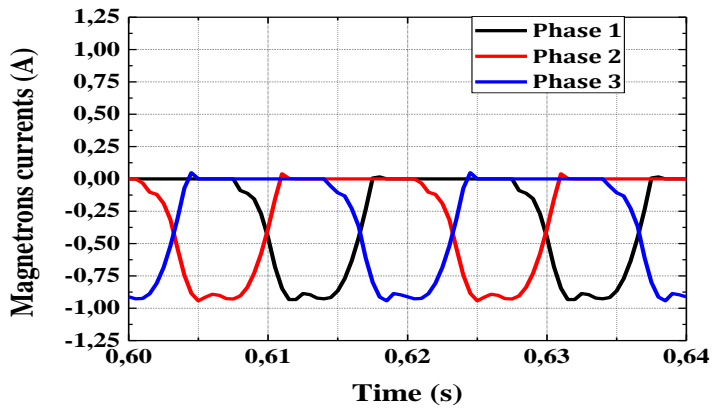



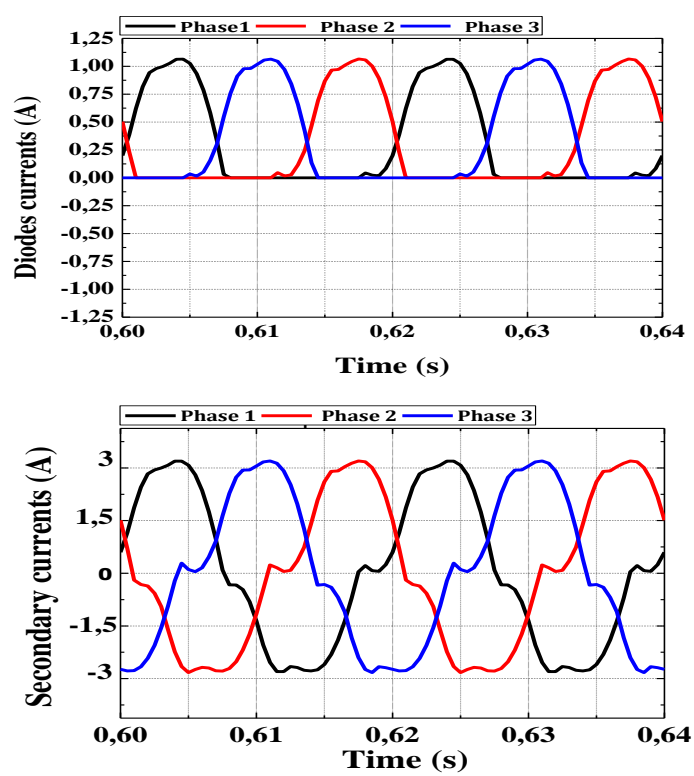

Fig 4. Result Obtained by Simulation of Magnetrons Currents, Diodes and Secondary.
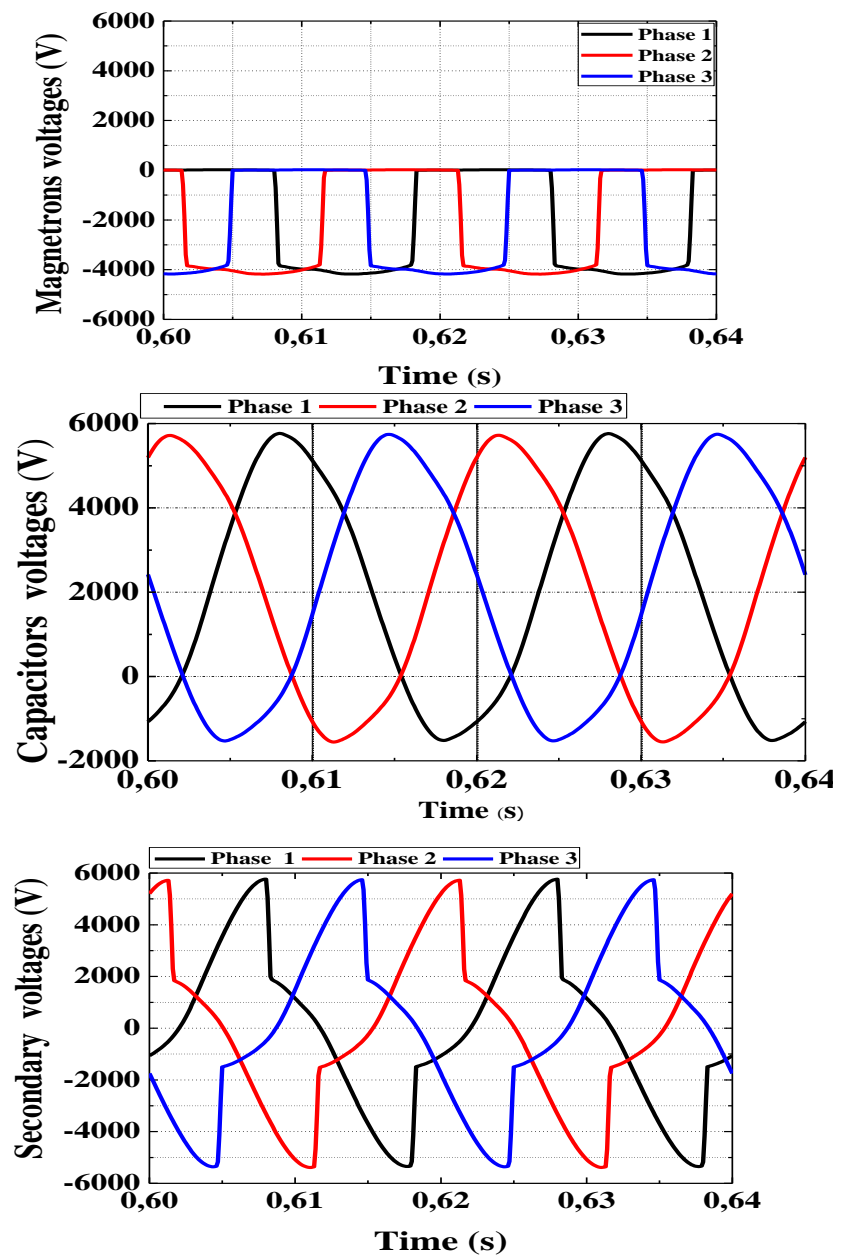

Fig 5. Result Obtained by Simulation of Magnetrons Voltages, Capacitors and Secondary.

\section{OPTIMIZATION OF THE TETRAHEDRAL TRANSFORMER USED IN THE POWER SUPPLY}

The optimization stage is based on the model developed on Matlab/Simulink of the three-phase HV power supply with three-magnetron per phase. This model will allow us to study with respect to the reference transformer case (non-optimized transformer) the sensitivity of each geometrical parameter to the nominal operation of the power supply [11-13]. This study will give us an idea of how we can simultaneously vary all the parameters in order to meet the following criteria:

- Have the various possible optimal solutions that offer a reduced volume without risk of exceeding the limits recommended by the magnetron manufacturer.

- Among the obtained solutions, find a better optimal one that respects the full power operation of the magnetrons.

\section{A. Influence of each Single Transformer Parameter on the Magnetron Current}

The $\pi$ quadruple model of the three-phase tetrahedral HV transformer contains non-linear inductances that depend on the geometrical parameters. Therefore, the variation of such a parameter modifies the overall operation of the equivalent circuit of the power supply. The simulation results of the model permit to plot the variation of the maximum and average magnetron current in terms of the selected transformer parameters as shown in Fig. 6 to 10. These parameters must be within the ranges specified in Table I.

TABLE I. VARIATION RANGE OF THE PARAMETRER

\begin{tabular}{|l|l|}
\hline Name of the parameters & Rating values \\
\hline $\mathrm{a}(\mathrm{mm})$ & $45 \leq \mathrm{a} \leq 75$ \\
\hline $\mathrm{n}_{2}$ & $2000 \leq \mathrm{n}_{2} \leq 2800$ \\
\hline $\mathrm{n}_{3}$ & $10 \leq \mathrm{n}_{3} \leq 18$ \\
\hline e $(\mathrm{mm})$ & $0,45 \leq \mathrm{e} \leq 1,05$ \\
\hline
\end{tabular}
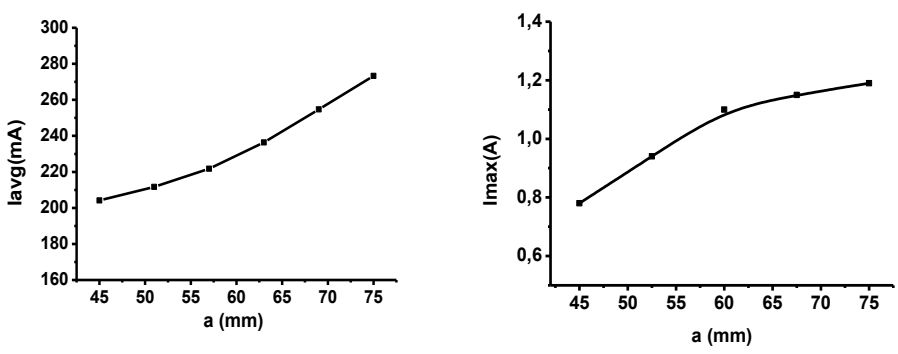

Fig 6. Magnetron Current Simulation Results as a Function of «a».
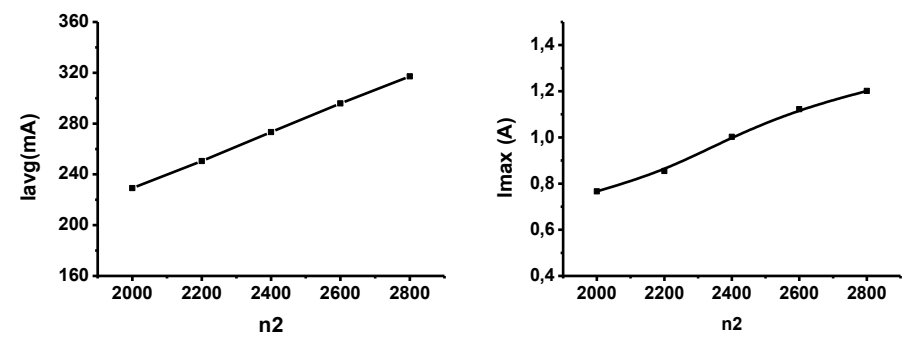

Fig 7. Magnetron Current Simulation Results as a Function of $« \mathrm{n}_{2} »$. 

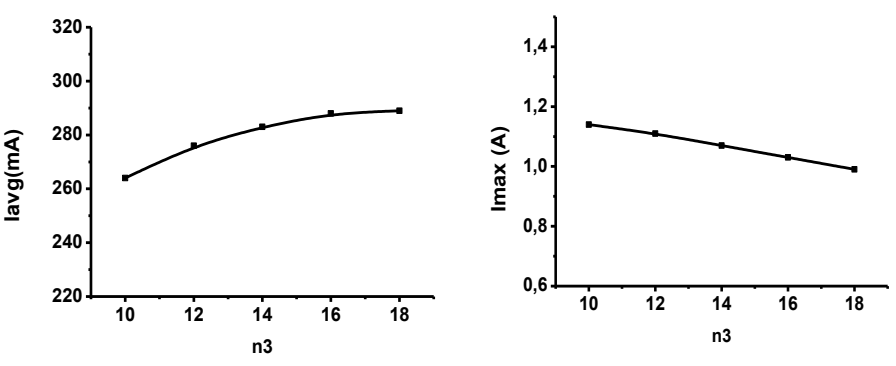

Fig 8. Magnetron Current Simulation Results as a Function of « $\mathrm{n}_{3} »$.
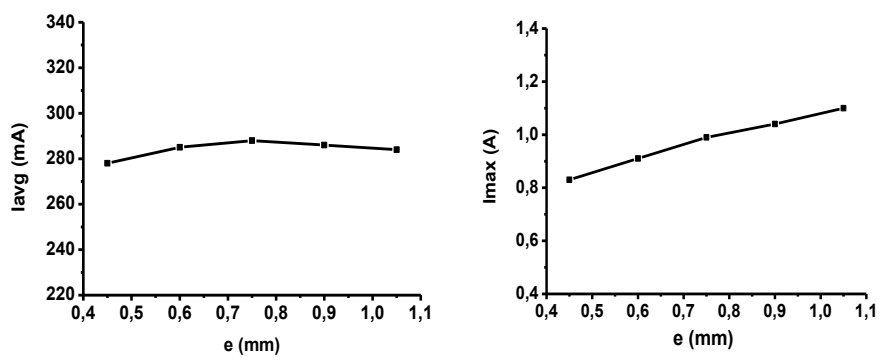

Fig 9. Magnetron Current Simulation Results as a Function of «e».

From Fig. 6 to10, we can see that the maximum current and the average magnetron current decreases when the three parameters $\left(\mathrm{a}, \mathrm{n}_{2}, \mathrm{e}\right)$ decrease. On the other hand, for the case of the $n_{3}$ parameter, we notice that the increase in the number of plates constituting each shunt causes a decrease in the maximum value of the current in the magnetrons. We also note that the variation of $n_{3}$ does not exceed the acceptable limits of the magnetron current mean value.

These observations make us think of reducing the magnetic circuit volume of the transformer, without risk of damaging the magnetron tubes.

\section{B. Optimization Algorithm}

The analysis of the results obtained previously confirms the magnetron current sensitivity with respect to the variation of each geometrical parameter of the transformer. These results prompted us to define an algorithm to study the influence of more than one geometrical parameter on the electrical operation of the power supply. We seek to simultaneously minimize all the parameters $\left(\mathrm{a}, \mathrm{n}_{2}, \mathrm{n}_{3}\right.$, e) thus the total volume of the tetrahedral transformer. The different optimal solutions found allow us to make a better choice between the transformer volume and the average power output by the magnetron.

The algorithm is used to minimize an objective function, which is the volume of the transformer in $\left(\mathrm{cm}^{3}\right)$ while respecting the operating conditions of the three phase magnetron power supply. The objective volume function is defined in the following form:

$V_{\text {transformer }}=V_{\text {core }}+V_{\text {copper }}$
From Fig. 2, $V_{\text {core }}$ can be calculated as follows:

$V_{\text {core }}=3 \times[$ ( Total volume of the magnetic circuit $)$ + (Volume of the stack of shunts)

- (Total volume of the winding window)]

$V_{\text {core }}=3 \times[(6 \mathrm{a} \times 5 \mathrm{a} \times \mathrm{b})+(2 \times(\mathrm{a} \times \mathrm{b} \times \mathrm{h}))-(2 \times$ $a \times b \times(3 \times a))]$

The volume of the copper is defined by :

$V_{\text {copper }}=3 \times\left\{S\left[E_{\text {coil } / \text { colum }}\left[\sum_{i=0}^{E_{\text {coil } / \text { colum }}}(b+a+4 d * i)\right]+\right.\right.$

$\left.\left(N_{\text {coil } / \text { colum }}-E_{\text {coil } / \text { colum }}\right)(b+a+4 d(i+1)]\right\}$

- $\mathrm{d}$ : presents the diameter of the copper cable on the primary or secondary side

- $N_{\text {coll/colum }}:$ presents the number of turns per column

- $E\left(N_{\text {coll/colum }}\right):$ presents the entire part of $N_{\text {coll } / \text { colum }}$

- $N_{\text {coll/colum }}-E\left(N_{\text {coll/colum }}\right)$ : presents the fractional part of $N_{\text {coll } / \text { colum }}$

By using the different intervals of variation of the geometrical parameters defined previously. The vector X used in our algorithm (Fig. 10) will take all the possible combinations between the different parameters $\mathrm{X}=\left[\mathrm{x}_{1}, \mathrm{x}_{2}, \mathrm{x}_{3}\right.$, $\left.\mathrm{x}_{4}\right]=\left[\mathrm{a}, \mathrm{n}_{2}, \mathrm{n}_{3}\right.$, e]. Table II gives the step and the variation margin of each combined and defined parameter in the vector $\mathrm{X}$.

TABLE II. STEP AND VARIATION MARGIN OF EACH PARAMETER

\begin{tabular}{|l|l|l|l|}
\hline Name of the parameters & Start & Step & End \\
\hline $\mathrm{a}(\mathrm{mm})$ & 45 & 5 & 75 \\
\hline $\mathrm{n}_{2}$ & 2000 & 100 & 2800 \\
\hline $\mathrm{n}_{3}$ & 10 & 2 & 18 \\
\hline $\mathrm{e}(\mathrm{mm})$ & 0,45 & 0,15 & 1,05 \\
\hline
\end{tabular}

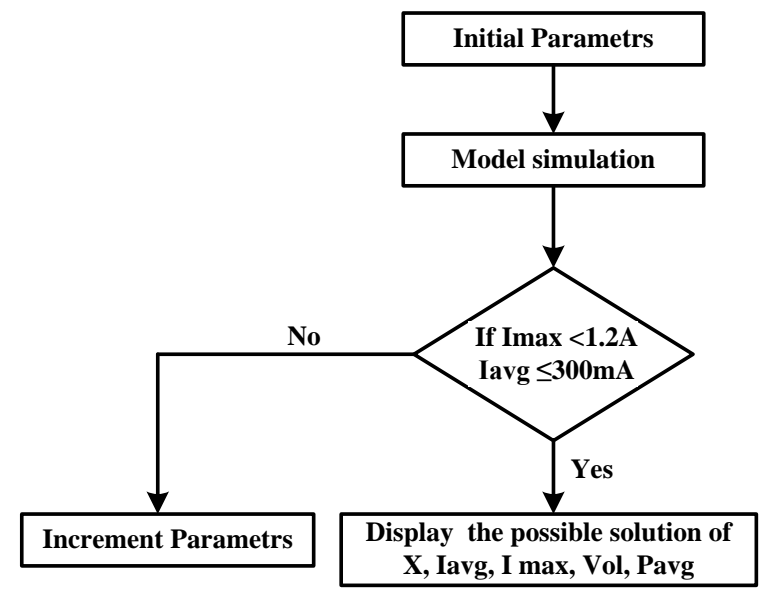

Fig 10. Different Steps of Optimization Algorithm. 
TABLE III. Best SOLUtion ObTAINED By the OPtimizATION ALGORITHM

\begin{tabular}{|l|l|l|l|l|l|l|l|l|}
\hline & $\begin{array}{l}\mathrm{a} \\
(\mathrm{mm})\end{array}$ & $\mathrm{n}_{2}$ & $\mathrm{n}_{3}$ & $\begin{array}{l}\mathrm{e} \\
(\mathrm{mm})\end{array}$ & $\begin{array}{l}\text { Imax } \\
(\mathrm{A})\end{array}$ & $\begin{array}{l}\text { Iavg } \\
(\mathrm{mA})\end{array}$ & $\begin{array}{l}\text { Pavg } \\
(\mathrm{w})\end{array}$ \\
\hline ref & 75 & 2400 & 18 & 0,75 & 0,95 & 271,17 & 9988,36 & 1100,47 \\
\hline $\mathrm{S}_{1}$ & 75 & 2400 & 18 & 0,45 & 0,95 & 271,17 & 9989,01 & 1100,47 \\
\hline $\mathrm{S}_{2}$ & 65 & 2600 & 10 & 0,75 & 0,91 & 264,34 & 7788,87 & 1074,60 \\
\hline $\mathrm{S}_{3}$ & 70 & 2400 & 10 & 0,75 & 0,90 & 259,73 & 8834,97 & 1054,61 \\
\hline $\mathrm{S}_{4}$ & 70 & 2400 & 16 & 1,05 & 0,84 & 256,53 & 8859,06 & 1036,58 \\
\hline $\mathrm{S}_{5}$ & 55 & 2800 & 14 & 0,45 & 0,79 & 244,85 & 5925,99 & 983,47 \\
\hline
\end{tabular}

At each $\mathrm{X}$ iteration, we perform a model simulation on Simulink using the "sim" function in Matlab. The results obtained from each simulation will be checked in order to take the one that respects the operating constraints of the power supply. By displaying to each solution found the values of vector $\mathrm{X}$, the max and average current as well as the average power of the magnetron.

After simulating the model with the different combinations of the geometrical parameters, Table III presents the five best solutions selected that meet the current imposed by the manufacturer also that it allows to operate the magnetrons in nominal power.

From Table III, we find that solution $S_{2}$ presents the best compromise between the volume of the transformer and the operation of the magnetron $(\mathrm{Pavg}=1074,6 \mathrm{~W}, \operatorname{Imax}=0.91(\mathrm{~A})$ and Iavg $=264,34 \mathrm{~mA}$, Volume $\left.=7788,87 \mathrm{~cm}^{2}\right)$. For the solution $\mathrm{S}_{5}$, it has a minimum volume, but it does not allow nominal operation at full power of the magnetrons.

We simulate the model under Matlab/Simulink with the new geometrical parameters of the transformation optimization solution. The waveforms of the voltages and currents obtained (Fig. 11 and 12) are almost identical to those obtained in the case of reference, while respecting the operating constraints of the magnetrons. So we can say that $22 \%$ of the power supply volume is optimized without having a large magnetron power lost after optimization.

Transformer optimization rate $(\tau)$.

$\tau=\frac{\text { Vref-Vopt }}{\text { Vref }}=\frac{9988,36-7788,87}{9988,36}=0,22$

Magnetron power lost after optimization $\left(\mathrm{P}_{\text {lost }}\right)$.

$\mathrm{P}_{\text {lost }}=\mathrm{P}_{\text {mref }}-\mathrm{P}_{\text {mopt }}=1100,47-1074,60=25,87 \mathrm{~W}$

$\mathrm{P}_{\text {mref }}$ : Average magnetron power given by the reference transformer.

$\mathrm{P}_{\text {mopt }}$ : Average magnetron power given by the optimized transformer.
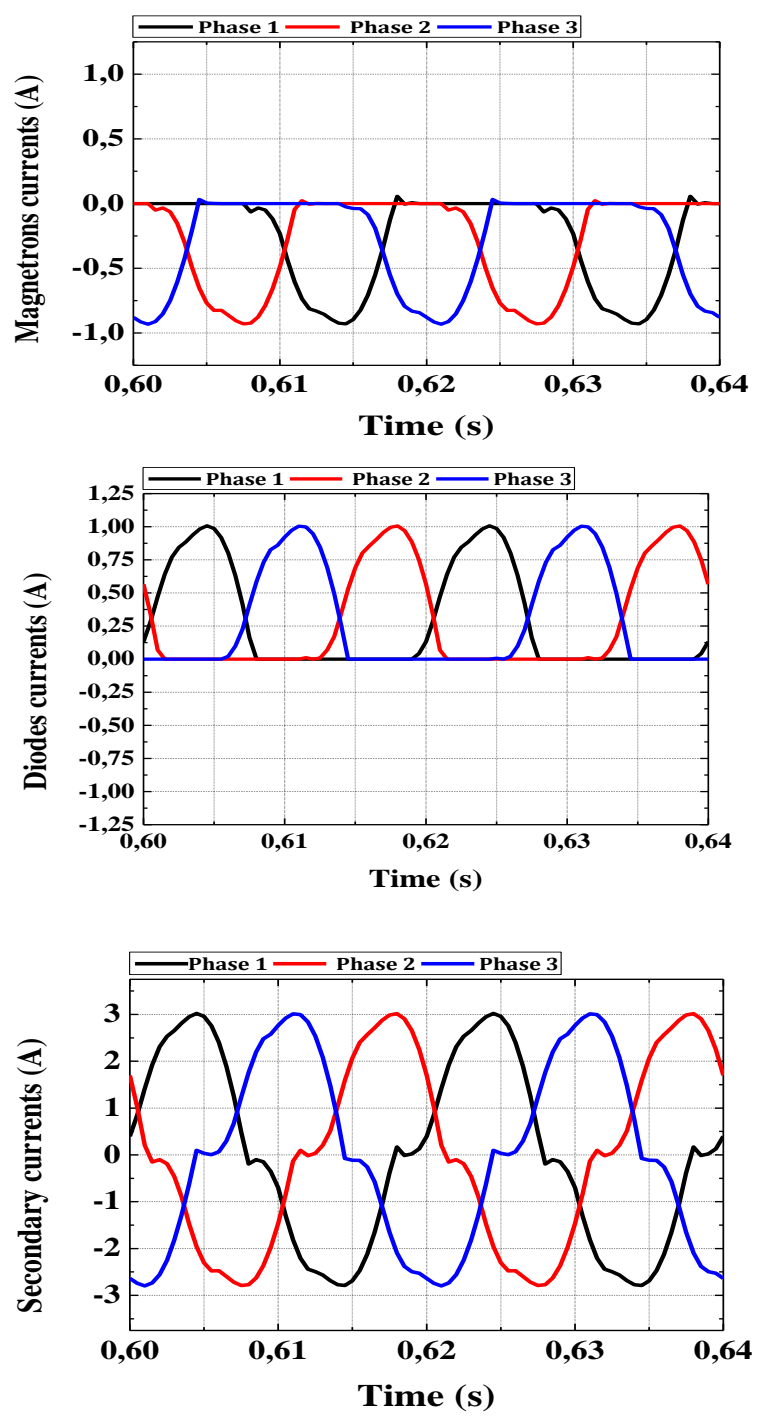

Fig 11. Results Obtained by Simulation of the Model Optimized. Currents of Magnetrons, Diodes and Secondary. 

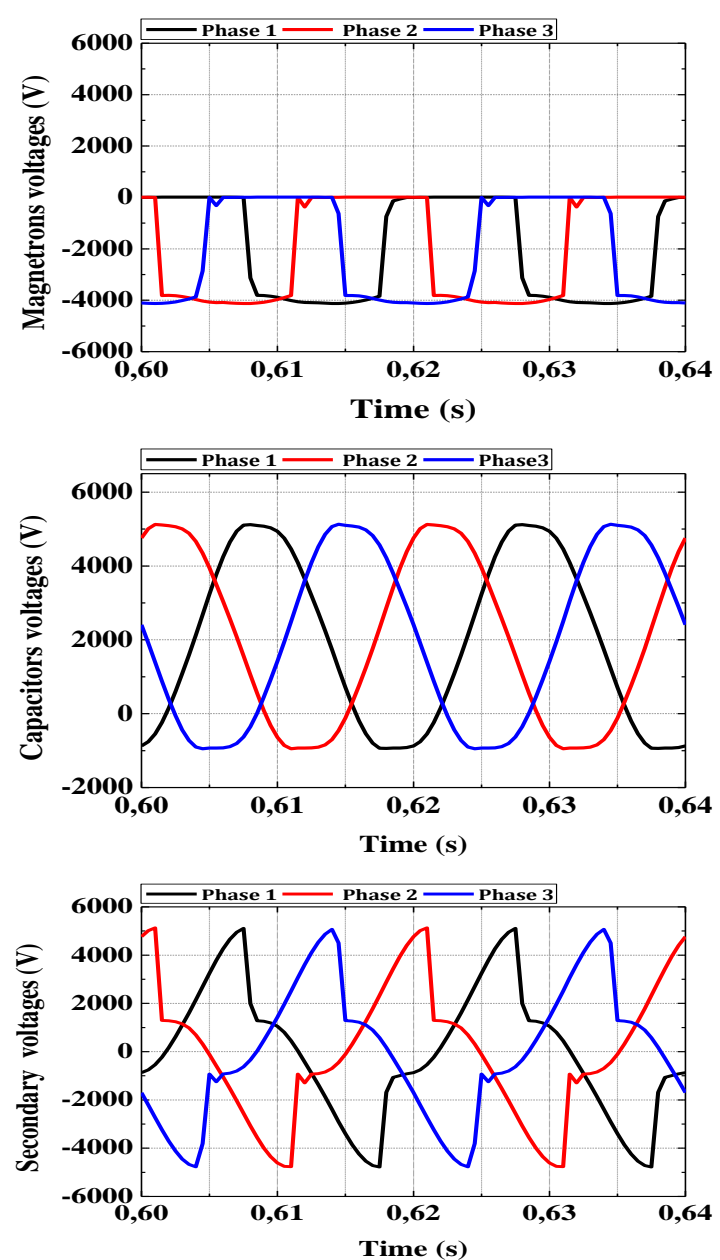

Fig 12. Results obtained by Simulation of the Model Optimized. Voltages of Magnetrons, Capacitors and Secondary.

\section{CONCLUSION}

In this work, we have succeeded after a study of optimization, to define a proper algorithm that aims to find an optimal solution of the three-phase tetrahedral type $\mathrm{HV}$ transformer used to feed three magnetrons per phase. This study allowed us to reduce the volume, the congestion as well as the cost. The optimized solution obtained is compared to that of reference; it gave a transformer that meets the operating criteria of the entire power supply.

As a perspective, this work can be used as a reference to optimize another type of transformer employed for microwave application at $\mathrm{N}=1,2,3$ magnetrons per phase while seeking to do a thermal study on the optimized transformer.

\section{REFERENCES}

[1] Elghazal, M. Ould ahmedou, M. Chraygane, M. Ferfra, A. Belhaiba. Optimization of high voltage power supply for industrial microwave generators for one magnetron. Journal of Theoretical and Applied Information Technology, 2012, vol. 46, no 1, pp. 001-010.

[2] H.Outzguinrimt, A.Bouzit, M.Chrayagne, M.Lahame, R.Oumghar, M.Ferfra. Design and Modeling of New Configuration of Three Phase Transformer For High Voltage Operation Using in Microwave Industrial. In : 2018 International Conference on Electronics, Control, Optimization and Computer Science (ICECOCS). IEEE, p.1-6.

[3] Naama El Ghazal, M. Chraygane, M. Ferfra, A. Belhaiba, M. Fadel, B. Bahani," Modeling of New Three-phase High Voltage Power Supply for Industrial Microwave Generators with One Magnetron Per Phase" International Journal of Electrical and Computer Engineering (IJECE), Vol. 3, No. 2 , pp. 270-278, April 2013.

[4] M.Lahame, M.Chraygene, H.Outzguinrimt, R.Batit, R.Oumghar, M.ferfra. Modeling Under MATLAB by ANFIS of Three-Phase Tetrahedral Transformer Using in Microwave Generator for Three Magnetrons Per Phase. Telkomnika, vol. 16, no.5, pp. 2406-2414, 2018.

[5] B.Bahani, A. Bouzit, M.Chraygane, M.Ferfra, N. El Ghazal, A. Belhaiba .Modeling of a New High Voltage Power Supply for Microwave Generators with Three Magnetrons. International Journal of Electrical \& Computer Engineering (IJECE). vol. 3, no.2, pp.2088-8708, 2013.

[6] Guanghao Liu, Xiao-Bang Xu. "Improved Modeling of the Nonlinear B-H Curve and Its Application in Power Cable Analysis". IEEE Transaction on Magnetics, ; 38(4), 2002.

[7] Z.Zhao, F.Liu, Z.Cheng, W.Yan, L.Liu ,J.Zhang, Y.Fan. Measurements and Calculation of CoreBased B-H Curve and Magnetizing Current in DC-Biased Transformers. IEEE Transactions on Applied Superconductivity. vol .20 ,no.3, pp. 1131-1134, 2010.

[8] M.Bassoui, M.Ferfra, M.Chraygane. Improved modeling of a singlephase high voltage power supply for microwave generators for one magnetron. J Electr Eng, vol.16, no.4, 2016.

[9] M.Buragohain, C.Mahanta . A novel approach for ANFIS modelling based on full factorial design. Applied soft computing, vol.8, no.1, pp. 609-625, 2008.

[10] O.Kisi, Suspended sediment estimation using neuro-fuzzy and neural network approaches. Hydrological Sciences Journal, vol.50, no.4, pp. 683-696, 2005.

[11] M.Ould.Ahmedou, M.Ferfra, N.EL Ghazal, M.Chraygane,M. Maaroufi "Implementation and Optimization Under Matlab Code of a HV Power Transformer For Micowave Generators Supplying Tow Magnetrons", Journal of Theorical and Applied Information Technology, vol. 33 ,no.2, 30 November 2011.

[12] A. Belhaiba, N. Elghazal, M. Chraygane, M. Ferfra, B. Bahani, M.ould Ahmedou "Improved optimization of the Nominal Functioning of a High Voltage power supply $\mathrm{N}=2$ mangnetrons for microwaves generators". International Journal of Electrical and Computer Engineering(IJECE),vol.2, no.5,pp.708-716,October 2012.

[13] H.Satoru, H.Tomoyuki, M.Mitsunori. Hybrid optimization using DIRECT, GA, and SQP for global exploration. IEEE Congress on Evolutionary Computation. pp.1709-1716, 2007. 